ÉGYPTE monde arabe

\section{Égypte/Monde arabe}

12-13 | 1993

Une économie en transition

\title{
Une économie en transition. Introduction
}

\section{Louis Blin}

\section{(2) OpenEdition}

\section{Journals}

Édition électronique

URL : https://journals.openedition.org/ema/1239

DOI : 10.4000/ema.1239

ISSN : 2090-7273

\section{Éditeur}

CEDEJ - Centre d'études et de documentation économiques juridiques et sociales

\section{Édition imprimée}

Date de publication : 31 mars 1993

Pagination : 7-9

ISSN : 1110-5097

\section{Référence électronique}

Louis Blin, « Une économie en transition. Introduction », Égypte/Monde arabe [En ligne], 12-13| 1993,

mis en ligne le 08 juillet 2008, consulté le 07 juillet 2022. URL : http://journals.openedition.org/ema/ 1239 ; DOI : https://doi.org/10.4000/ema.1239

Ce document a été généré automatiquement le 7 juillet 2022.

Tous droits réservés 


\title{
Une économie en transition. Introduction
}

\author{
Louis Blin
}

1 Après avoir connu une croissance réelle du produit intérieur brut de $9 \%$ par an entre 1974 et 1984, due à des facteurs essentiellement externes, l'économie égyptienne a stagné pendant des années en dépit d'une aide extérieure massive, ce qui a conduit à une crise financière ayant nécessité la mise en œuvre, à partir de 1991, d'un programme de stabilisation économique et d'ajustement structurel. Ce programme de restructuration d'ensemble et de libéralisation globale, et non partielle comme lors de l'infitah sadatienne, a pour enjeu la transition d'une économie rentière dirigiste à une économie de production internationalisée.

2 Rentière, l'économie égyptienne l'est à plusieurs titres. Ce trait constitue la plus marquante de ses spécificités, qu'analyse Bruno Cabrillac dans l'étude macroéconomique qui ouvre ce numéro. Lorsqu'on évoque la rente dont bénéficient nombre de pays arabes, on pense pétrole. Ce dernier n'est en Égypte que l'un des facteurs d'une rente qui est également géographique (l'isthme de Suez), humaine (les travailleurs émigrés) et politique (l'aide extérieure). Cette caractéristique "multi-rentière " de l'économie égyptienne représente un atout, puisque ses ressources externes s'en trouvent diversifiées, donc moins vulnérables à la conjoncture, mais aussi un handicap, l'orientation rentière de l'activité économique et ses effets pervers se diffusant par de multiples canaux.

3 Or, les ressources de rente ne sont par définition pas liées à un travail interne, ce qui les rend aléatoires. Ma propre étude de la plus «classique » d'entre elles, la rente pétrolière, met en évidence la nécessité pour l'Égypte de s'adapter continuellement à l'évolution du marché pétrolier mondial si elle entend poursuivre ses exportations de pétrole, même si elle n'en tire en conséquence que des revenus proportionnellement décroissants. L'utilité économique d'exporter du pétrole tend alors à diminuer, à mesure surtout qu'augmente l'efficience de son emploi local. La tendance à la substitution d'une rente pétrolière externe par une rente interne, prélevée sous forme de taxation de la consommation énergétique, pourrait s'accompagner d'une 
modification de l'influence du secteur pétrolier sur l'économie dans le sens d'une amélioration de sa productivité. Ceci permettrait de passer de l'exportation de matières premières à celle de produits manufacturés. C'est donc à propos du type de rente que l'Égypte verra disparaitre le plus rapidement qu'est illustrée ici la problématique de la transition d'une économie de rente à une économie de production.

Un biais intéressant pour évaluer les possibilités de succès de ce processus est d'analyser l'activité des sociétés étrangères en Égypte, puisqu'elles sont originaires de pays non rentiers et qu'elles $\mathrm{y}$ sont donc confrontées à des problèmes spécifiques. L'étude de Steffen Wippel montre que les investissements allemands en Égypte, qui sont en majeure partie réalisés dans l'industrie de transformation - secteur productif par excellence - par des entreprises de taille moyenne, ont été très conséquents pour un pays du tiers monde après 1974, puis ont régressé à partir de 1984, année marquant le début de la crise de l'économie de rente. La présence entrepreneuriale de l'Allemagne en Égypte est devenue minime (26 participations au début de 1922 hors pétrole) et a été dépassée par celle de la France, dont les investissements sont le fait d'entreprises de taille plus importante. L'examen des difficultés rencontrées par l'investisseur étranger en Égypte - le cas allemand pouvant ici être généralisé - indique qu'elles ne tiennent pas à la législation régissant ses activités mais au cadre politique, économique et juridique, qui n'est pas propice aux activités de production. Dans ces conditions, la pérennité de l'investissement étranger dépend également de la captation d'une ressource de rente, en l'occurrence l'aide distribuée par le pays d'origine. C'est pourquoi seules les grosses sociétés influentes dans les pays bailleurs de fonds peuvent greffer leur activité en Égypte sur ce flux, ce qui expliquerait que la France ait dépassé l'Allemagne. Ceci va à rencontre de leur intégration locale et de leur contribution éventuelle à bâtir une économie de production.

Ce manque de conformité de l'activité économique égyptienne aux standards occidentaux est la cause du succès des cabinets de juristes d'affaires décrits par l'enquête de Jean-Claude Delaunay. La complexité des transactions avec les sociétés égyptiennes nécessite un savoir-faire particulier qui assure leur rentabilité. "Médiateurs obligés des échanges économiques", ces cabinets sont les fruits de l'infitah, mélange de dirigisme et de libéralisme où le capital relationnel compte plus qu'ailleurs. Sont-ils adaptés à une économie en transition vers les normes internationales? On peut penser que leur expérience des firmes étrangères les a préparés mieux que quiconque au fonctionnement d'une économie de production. Leur fonction de conseil, plus importante que celle des cabinets équivalents en Occident en raison des spécificités de l'économie égyptienne, pourrait dans ce contexte se redéployer au bénéfice des sociétés locales, notamment celles qui veulent exporter. Les acteurs de la transition économique pourront-ils jouer leur rôle?

\section{INDEX}

Mots-clés : économie 
AUTEUR

LOUIS BLIN

Cedej 